\title{
Problems and technologies of remote access to unified information space of urban pipeline systems
}

\author{
Alexander Alekseev ${ }^{1}$ and Egor Mikhailovsky ${ }^{1, *}$ \\ ${ }^{1}$ Melentiev Energy Systems Institute of Siberian Branch of the Russian Academy of Sciences (ESI SB \\ RAS), Department of Pipeline Systems, 130, Lermontov Str., Irkutsk, Russia, 664033
}

\begin{abstract}
The paper presents the experience of applying modern information technologies while operating the urban pipeline systems. Consideration is given to the main problems interfering with ensuring the efficient modes of pipeline systems operation that are caused by uncertainty and inconsistency of information on the actual condition of the system that, in turn, are originated by different technological factors. The paper also pays attention to the lack of continuity, inconsistency and duplication of data in different software packages (accounting, billing, resources planning and management, geo-information systems, SAPR, SCADA, digital models of pipeline systems, etc.) used by companies, which complicates operation of pipeline systems. The paper discusses advantages of development and introduction of unified information space in a company, related problems of its updating, and methods of remote access to it. Causes originating this problem are analyzed and ways for its solution are searched for from the standpoint of the latest information technologies. For solving this problem the authors propose specialized software that implies active use of wireless communication channels, mobile devices, etc. This mobile information package is briefly described as a prototype intended for remote access to unified information space of a company and to a digital model of the pipeline system in particular using mobile communication devices. Considered are the advantages of this development and scenarios of its application.
\end{abstract}

\section{Introduction}

Modern urban pipeline systems (PS) are complex technological systems whose efficient operation affects quality and reliability of heat, water and gas supply for population, industrial and social facilities. Efficient operation of power systems is complicated by their dimensions, uncertainty and inconsistency of information on their actual condition, continuous changes in the system's structure and parameters due to its modification, repair and wear. The major way of overcoming these problems both in Russia and abroad is creation of intelligent PS [1-3]. Those facts not only generate new challenges related to adaptation of PS to a new elemental and technological base, but they also give way to new

${ }^{*}$ Corresponding author: egor.isem@ mail.ru 
potentials for their management owing to availability of new information technologies, methods of mathematical modeling and computer simulation [4], and to use of artificial intelligence [5,6]. Application of new PS management technologies requires appropriate informational support. Companies operating pipeline systems today have a large number of independent informational systems (accounting, billing, resources planning and management, geo-information systems, SAPR, SCADA, digital models of pipeline systems, etc.) each having their own manner of data storage and transfer; they are used and supported by different company's divisions each pursuing their own tasks. Information is often duplicated, it is inconsistent, needs parallel support of identical data in different software, which hampers timely use of available information for processes management.

These problems can be solved by creating unified information space (UIS) of a company that would allow timely access of all the company's divisions and specialists to any information available in the company, which would drastically enhance the processes management $[7,8]$. Creation of such a space is one of the priory objectives in the sphere of information system development for companies operating pipeline systems.

Due to a large scale of pipeline system (many thousands kilometers), there arises the problem of UIS remote access of company's specialists dealing with PS maintenance. To ensure such an access the appropriate applications are being developed in Russia (e.g., ZuluGIS Online), which proves their relevancy. UIS access at any time from any point of an operated facility requires availability of mobile devices of Smartphone or Tablet type, appropriate software and applications, developed infrastructure of wireless communication whose performances are not always satisfactory. On the background of problems related to creation of UIS the paper considers application of approaches developed by the author, including methods of remote UIS access and their relevancy.

\section{Unified information space of a company}

Review of UIS creation technologies [9-12] shows that universal software of ERP (Enterprise Resource Planning) and MRP (Manufacturing Requirement Planning) type is most often used for the space creation [8,13], particularly such as «Oracle E-Business Suite», «IBM Info Sphere», «SAP», «Microsoft Dynamics», «1C ERP», «Galaktika», and «Parus». Informational resources designed for computerization of document flow, economic activity of the company and PS management in this case remain independent. UIS concept proposed by the authors $[9,14,15]$ (on the base of ANGARA information and computation medium $[16,17]$ ) is aimed at consolidation of such informational resources, including data on PS process diagrams and parameters, telemetry data, commercial accounting data, contracted terms with customers and related companies, etc., thus ensuring PS data completeness and certainty (avoidance of data duplication and inconsistency), data accessibility, overall support of computational and analytical problems of different territorial and time levels of management on the unified informational base, as well as flexibility of UIS development and application.

Company's specialists get an access to all the information available both in the local and in the global Internet network that is required for making managerial decisions. But efficiency of UIS remote use to a great extent depends on availability and transmission capacity of wireless communication channels and requires development of special applications.

\section{Analysis of UIS remote access problems}

Common communication channels of $802.11 \mathrm{n}$ (Wi-Fi) standard allow transmission of 
datain the amount sufficient for downloading a model $(\sim 300 \mathrm{Mb}$ for diagrams with tens of thousands of nodes, and for maps) within the acceptable time (several seconds). Operating radius of residential transmitting stations of this standard is limited by tens of meters, and signal quality depends on the receiver location. Moreover, the coverage area in the city is limited by separate buildings where receivers are located. Networks of mobile operators, on the contrary, have no this disadvantage as they cover the entire city area and area beyond it. Despite theoretically sufficient data transmission rate as per $3 \mathrm{G} / 4 \mathrm{G}$ standards, in practice it also depends on the receiver location, load of communication channels and on other factors; moreover, tariffs of mobile operators per $1 \mathrm{~Gb}$ of data transmitted are higher than those of $802.11 \mathrm{n}$ standard. A number of papers are devoted to this issue; they consider it both from the standpoint of mobile devices development [18], and technologies for large data arrays transfer [19].

Two scenarios of UIS interaction with mobile devices are proposed subject to such technical conditions that require installation of special software for using digital models (Fig. 1):

1) a conservative scenario - it implies software-based adherence of a mobile device to some responsibility zone (operating area), and data downloaded from a digital model are limited by that area. Data of a mobile device and DB shall be synchronized at every connection of the device to a local network of the company without transfer of data updates via the mobile network;

2) a complete scenario - it implies synchronization of data on PS between mobile devices and DB of a company via mobile and local networks (including with territorial constraints) when codifying the data transmitted.

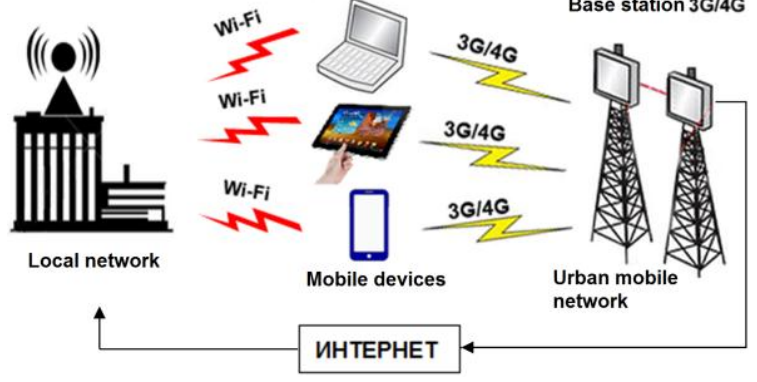

Fig. 1. A diagram of wireless access of mobile devices to local network of the company.

\section{Implementation of remote access to UIS}

For working with PS UIS using mobile devices of Smartphone or Tablet type, specialized software is needed with the following capabilities: presentation of PS model as a graphical scheme of a network; access to parameters of the scheme's elements; downloading the maps of the area and their matching with the PS model; satellite navigation over the area; search of PS network elements by the address or value of an arbitrary parameter; technical comments on the PS model with reference to the area (coordinates); automatic synchronization of a mobile copy of the PS model with ANGARA data base located in UIS.

ANGARA mobile informational complex based on the Windows operating system with sensor control capability has been developed in Melentiev Energy Systems Institute. 'Windows' system has been selected as it facilitates the software development and debugging, ensures compatibility of the office and mobile versions of Windows, availability of inherited components, etc. on the base of means for applications development, such as Windows Presentation Foundation and .NET Framework. 
Orientationof the mobile informational complex (MIC) at cross-platform architecture would undoubtedly allow using mobile devices of arbitrary configuration with the most common operating systems, which is a subject of future MIC development.

Graphic interface of a MIC user is given in Fig. 2. There are two methods for storage and development of PS scheme images (and images of other facilities) on the mobile device and on the computer. The vector one, i.e., data are stored in the form of coordinates that are used for making an image using given characteristics as, for example, in the 2GIS software. It ensures the most compact data storage and allows program interaction with separate elements of the image. A raster scan method allows data storage in the form of fragmented raster-scanned images (tiles) that form a final image of an object for each specified scale (as in Google Maps or in Yandex Maps). The latter approach allows saving the computational resources when forming the final image but does not imply frequent data change and, hence, frequent image fragments change. Since PS model is continuously updated, it requires repeated formation of such fragments at every change in the data and slows down generation of the result. MIC has integrated both approaches, i.e., a map is downloaded in the 'tiles' format and PS scheme (overlapping the map) is downloaded in the vector format.

A special-purpose version of ANGARA database is used in a mobile device as an independent source of data on PS. This version is implemented in the form of standardized files consisting of field values from DB recorded in sequence, their type and sequence being agreed in a proprietary API-drive for MIC access. Standardized files considerably accelerate data downloading into the ram memory as rate of file downloading from internal Smartphone or Tablet storage is much higher than that from DB, to say nothing

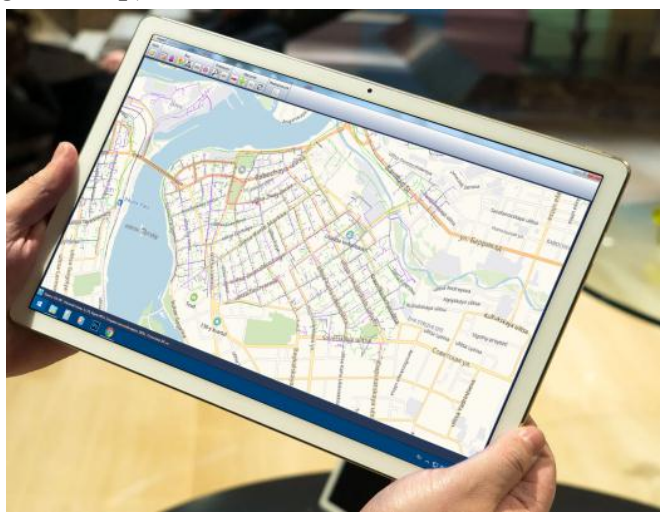

Fig. 2. Graphic interface of a MIC user. about local or mobile network. MIC operation is additionally optimized by excluding a set of data that do not belong to priority informational functions. For example, downloading a mobile version of PS model with dimensionality of tens of thousands of nodes into MIC on Tablets (even of low cost) with a dual-core processor of Atom type does not take more than 3 seconds. Compare: downloading on the notebook with a four-core Intel i3 processor takes $\sim 0.5 \mathrm{sec}$, whereas downloading of similar data from DB takes more than $1 \mathrm{~min}$. In case of downloaded data fragmentation by territorial feature the MIC efficiency is even higher.

The main advantage of MIC is an option of two-sided interaction with DB of a company. For example, during works on a pipeline, company specialists may record inadequacies in a digital model (location of standpipes, chambers, gate valves, air valves, etc.; length, diameters, materials of pipes and fittings, etc.) they may also use the mode of data accumulation on a specific mobile device. Such changes are automatically controlled by the pre-set rights of access to the company's DB. MIC incorporates a procedure of synchronization performed every time when a mobile device is connected to a local network of a company irrespective of its user. Results of such synchronization become immediately accessible to all the legitimate UIS users.

\section{Resolution}

Discussed was the problem of ensuring the remote access to UIS of a company operating the urban pipeline systems, at any time and from any point in the city. 
A mobile information complex developed in ESI SB RAS that ensures remote access to UIS has been characterized. The complex was developed on the base of ANGARA information and computation system using mobile devices and wireless communication channels. This application offers information and navigation functions, and functions for on-line updating of PS digital models.

The research was carried out within the project III.17.4.3 of the Fundamental research program of SB RAS (AAAA-A17-117030310437-4) with finance support of RFBR and the Government of Irkutsk Region in the framework of research project № 17-48-380021

\section{References}

1. Concept of the Energy Strategy of Russia till 2030 // Attachment to "Energy Policy" Journal, (2007)

2. On energy saving and raising the energy efficiency and on amendments to some legal acts of Russian Federation (RF Federal Law No 261-FZ dated 23.11.2009)

3. N.N. Novitsky. Urban Utilities. Technical sciences and Architecture, 101, 456 (2011)

4. N.N. Novitskiy, A.V. Alekseev, The Eleventh International Conference Computing and control for the Water Industry, 3, 901 (2011)

5. J.K. Ambrosio, B.M. Brentan, M. Herrera, E.Jr. Luvizotto, L. Ribeiro, J. Izquierdo, Mathematical Problems in Engineering. Article ID 9765468 (2019)

6. X. Lang, P. Li, Y. Li, H. Ren, Information, 8, 113 (2017).

7. F. Yu. Kassatkin, S.V. Kostylev, Water Supply and Sanitary Engineering, 6, 45 (2010)

8. A.V. Kritsky, D.S. Kargapoltsev, D.N. Brusnitsyn, S.V. Skorinov, D.P. Shaburov, A.E. Dobrazov, Water Supply and Sanitary Engineering, 11, 45 (2015)

9. A.V. Alekseev, N.N. Novitsky. Conference on mathematical models and methods of the analysis and optimal synthesis of the developing pipeline and hydraulic systems, 39 (04001), 1 (2018)

10. A.V. Alekseev, N.N. Novitsky, S.Yu. Obuzdin, Water Supply and Sanitary Engineering, 11, 54 (2017)

11. A.V. Ostroukh, D.O. Gusenitsa, V.B. Golubkova, P.F. Yurchik, IOSR-JCE, 16 (2,6), 31 (2014)

12. S. Oman, R. Leskovar, B. Rosi, A. Baggia, Technical Gazette, 24 (6), 1889 (2017)

13. M. Bajer, IJACEEE, 12 (4), 1 (2014)

14. A.V. Alekseev, N.N. Novitsky, Nauchny Vestnik NGTU, 2, 26 (2017)

15. A.V. Alekseev, N.N. Novitsky, V.V. Tokarev, Z.I. Shalaginova, Pipeline systems. Methods of mathematical modeling and optimization, 221 (2007)

16. A. Contan, C. Dehelean, L. Miclea, IEEE International Conference on AQTR 10.1109/AQTR.2018.8402699 (2018)

17. B. Stackpole, Automation World Contributing Writer, 1 (2016)

18. C. Shen, M. Yun, A. Arora, H.-A. Choi, Lecture Notes in Networks and Systems, 70, 634 (2020)

19. R. Siddavaatam, I. Woungang, S.K. Dhurandher, Advances in Intelligent Systems and Computing, 926, 713 (2020) 